\title{
Preemptive Kidney Transplantation in Patients with Diabetes Mellitus
}

\author{
Rajani Dinavahi, MD ${ }^{\mathrm{a}, \mathrm{b}}$, Enver Akalin, MD ${ }^{\mathrm{a}, \mathrm{b}, *}$ \\ ${ }^{a}$ Renal Division, Mount Sinai School of Medicine, New York, NY 10029, USA \\ ${ }^{\mathrm{b}}$ Recanati/Miller Transplantation Institute, Mount Sinai School of Medicine, \\ New York, NY 10029, USA
}

Twenty-one million patients, approximately $7 \%$ of the United States population, are affected by diabetes mellitus. The numbers continue to rise, and by 2025, diabetes will affect 300 million people worldwide [1]. Despite improvements in the management of proteinuric renal diseases and hypertension in the last decade, diabetes remains the most prevalent etiology for end-stage renal disease (ESRD) in the United States. Diabetic nephropathy as an etiology for ESRD accounted for just over 17\% of the United States dialysis population in 1980, but now comprises almost $45 \%$, a significant increase within 25 years [2].

Peritoneal dialysis, hemodialysis, and renal transplantation are the three mainstays of renal replacement therapy. Kidney transplantation is the most preferred treatment for ESRD, because it improves not only the patient's survival compared with dialysis, but also the quality of life. Although the mortality rates of dialysis patients have improved over time, $15 \%$ to $20 \%$ still die each year [2]. With advances in immunosuppressive medications and the care of transplant recipients, 1-year patient and graft survival have increased to over $95 \%$ and $90 \%$, respectively, and acute rejection rates have decreased to $10 \%$ to $15 \%$. As of December 2006, 74,000 patients were on the waiting list for kidney transplantation in the United States [3]. Only 16,481 patients, however, received kidney transplantation in 2005 (9913 deceased donor and 6568 living donor). Waiting times on the list vary considerably by region of the country, with the median wait time for patients who were listed in 2002 for renal transplantation being 1136 days. Waiting times for deceased donor transplantation more than 5 to 7 years are not

* Corresponding author. Mount Sinai Medical Center, One Gustave L. Levy Place, Box 1104, New York, NY 10029-6574.

E-mail address: enver.akalin@msnyuhealth.org (E. Akalin). 
uncommon in many metropolitan areas. Patients who have ESRD often are started on dialysis during these extended waiting times. Preemptive transplantation is transplantation performed before the initiation of renal dialysis. Preemptive transplantation occurred in $25 \%$ of adult living donor recipients and $10 \%$ of deceased donor recipients in the United States $[4,5]$. The rate is slightly higher in pediatric recipients, $34 \%$ and $14 \%$ of living and deceased donors, respectively, because of preferential allocation of deceased organs to pediatric recipients by the United Network for Organ Sharing (UNOS) point allocation system, and also to the increased availability of living donors to pediatric recipients. Obstacles to the performance of transplantation before the initiation of dialysis were lack of access to health care and timely referral to both nephrologist and transplant center. Preemptive transplantation in deceased donor recipients was performed less often due to prolonged waiting times. Recent observational studies have supported the benefits of preemptive transplantation in ESRD patients. This article summarizes the advantages of kidney transplantation compared with dialysis and the importance of early referral of patients with chronic kidney disease to transplant centers. It also discusses whether preemptive transplantation has any additional benefits to transplant recipients. Diabetic patients who have ESRD are also candidates for pancreas transplantation, either in the form of simultaneous pancreas and kidney transplantation (SPK) or pancreas after kidney transplantation (PAK), and the article discusses preemptive SPK in diabetic patients.

\section{Renal replacement treatment: dialysis versus transplantation}

Mortality rates across all age groups are 10- to 20 -fold higher in the dialysis population compared with the general population, with greater than $50 \%$ of that mortality being attributed to cardiovascular disease [2,6]. Cardiovascular disease risk increases across the spectrum of severity in chronic kidney disease, peaking in the ESRD population. There is an increased incidence of acute myocardial infarction, congestive heart failure, and sudden cardiac death in dialysis patients [2]. Twenty-seven percent of all causes of mortality in ESRD patients may be attributed to arrhythmias and sudden cardiac death. Hypertension and left ventricular hypertrophy are very common in patients who have ESRD. Risk of acute myocardial infarction, congestive heart failure, or sudden cardiac death appear to be greater in diabetics across all stages of chronic kidney disease and all modalities of renal replacement therapy, and these risks appear to increase exponentially in relation to the overall duration of dialysis. Overall, 5-year survival is only $27.2 \%$ in hemodialysis and $23.3 \%$ in peritoneal dialysis diabetic patients [2]. Cerebrovascular disease in ESRD patients is also significantly higher, with the overall incidence of stroke being $15 \%$, almost four times the general population. 
The association between cardiovascular disease and renal failure is explained in part by traditional risk factors shared by the both diseases, such as diabetes, hypertension, hyperlipidemia, smoking, and older age. Renal failure and ESRD, however, carry additional nontraditional cardiac risk factors that contribute to accelerated atherosclerosis, such as calcium phosphate deposition, secondary hyperparathyroidism, hyperhomocysteinemia, increased advanced glycation end products, volume overload, electrolyte abnormalities, and altered nitric oxide/endothelin levels [7]. Poor nutritional status, a chronic inflammatory state, thrombogenic factors, and altered immunologic function also may place these patients at additional risk.

Another important factor for the increased morbidity and mortality in ESRD patients is dialysis-related vascular access procedures and infection, totaling almost 1.5 million access procedures in the United States for ESRD patients in 2004. Over $50 \%$ of dialysis-related hospital admissions are secondary to dialysis access-associated infections [2].

Renal transplantation was shown to confer a survival benefit to the patient by Wolfe and colleagues [8] in a landmark 1999 article. The benefit was sustained across all races, ages, and primary causes of renal disease, establishing it as the standard of care for patients who had ESRD. This was a longitudinal study examining mortality in 228,552 dialysis patients. Of these, 46,164 patients were placed on a waiting list for deceased donor renal transplantation; 23,275 received a deceased donor transplant between 1991 and 1997. The annual death rate per 100 patient years was 2.8 in transplant recipients, compared with 6.3 in patients on the waiting list and 16.1 in dialysis patients not listed for transplantation. The projected increase in life expectancy by transplantation was 10 years overall (range 3 to 17 years, according to patient groups by age). Thirty-three percent of patients on the waiting list and $31 \%$ of transplant recipients were diabetic. Among the diabetic patients on the waiting list, the annual mortality rate was $11 \%$, and transplant reduced the risk of death by $73 \%$. The greatest increase in life expectancy in terms of the etiology of the ESRD was observed in diabetics (11 years, compared with 7 years among the patients with glomerulonephritis, and 8 years among those with other causes of ESRD). Further studies demonstrated an improved survival benefit in patients receiving marginal deceased donor organs and in obese recipients, as well as in patients outside the United States [9-12].

Cardiac disease progression appears to halt after successful renal transplantation and maintenance of graft function. Meier-Kriesche and colleagues [13] analyzed 60,141 primary renal transplant patients registered in the United States Renal Data System (USRDS) registry between 1995 and 2000 for cardiac mortality, and compared them with 66,813 adult dialysis patients on the waiting list. Although cardiovascular risk increases in the immediate postoperative period, this risk diminishes with time as long as renal function is preserved. This even held true in diabetic patients, where 
the cardiovascular death rates were about twice as high compared with nondiabetic patients. In contrast, the cardiovascular disease rates on the transplant waiting list increased progressively over time.

In addition to the morbidity and mortality benefits received by renal transplantation, the major economic advantage of renal transplantation makes it a significant medical and societal concern. Inpatient Medicare expenses for dialysis during 2004 reached $\$ 5.6$ billion, with outpatient costs reaching an astronomical $\$ 6.7$ billion [2]. ESRD patients with diabetes incur $33 \%$ overall higher costs than their nondiabetic counterparts, almost $\$ 72,000$ per patient per year in 2004 , the largest percentage of any single group. Although the cost of transplantation per patient per year is higher than dialysis during the first year after transplantation, it significantly reverses after the first year, and becomes cost-effective compared with dialysis [2]. Additionally, USRDS data showed 0.79 days of admission per patient-year for renal transplant recipients, versus almost 2 days of admission for patients receiving either hemodialysis or peritoneal dialysis.

\section{Referral to transplantation}

Because the risk of cardiovascular disease and mortality in dialysis patients is increased, prompt referral to renal transplant centers is a critical and life-saving step. The average waiting time for deceased donor transplantation is almost 3 years from listing, exceeding 5 to 7 years in some regions, so early listing is important to achieve prompt transplantation and decrease the time on dialysis. A prospective study at the University of Pennsylvania evaluated the factors affecting transplantation referral practices, where 129 patients had preemptive and 161 patients had nonpreemptive renal transplant evaluations [14]. Seventy-six percent of patients undergoing preemptive evaluation and $53 \%$ of patients undergoing nonpreemptive renal transplant evaluation stated that the person most influential in their decision to undergo transplantation was their nephrologist. Preemptive group members saw their nephrologists an average of 71 months before transplant evaluation; nonpreemptive group members saw their nephrologists an average of 25 months before the initiation of dialysis. This study suggested the importance of early referral to nephrologists leading to early referral for transplant evaluation. Many patients, however, are not being seen by nephrologists until late into their course, thereby delaying the recognition of severe renal disease. Arora and colleagues [15] reported that late referral to the nephrologist was common at New England Medical Center and associated with poor pre-ESRD care.

A retrospective analysis using USRDS data of 38,836 primary kidney transplant recipients between 1995 and 1998 demonstrated that the factors associated with preemptive renal transplantation included Caucasian race, higher education, and coverage by private insurance versus Medicare [16]. 
Although the accepted UNOS guideline for placement onto renal transplant waiting lists in the United States is $20 \mathrm{~mL} / \mathrm{min}$, the average glomerular filtration rate (GFR) in the United States at the time of listing, is $9.9 \mathrm{~mL} / \mathrm{min}$, suggesting that patients are being referred later than necessary for a life-saving procedure. Referral to renal transplant centers should occur when GFR is under $30 \mathrm{~mL} / \mathrm{min}$, or if it is predictable that a patient's renal function will decline steadily.

\section{Preemptive kidney transplantation}

Although most transplants in the United States are performed after the initiation of dialysis, there has been much interest in the advantage of preemptive renal transplantation. Living transplantation more often occurs preemptively as there is no waiting time, and it has superior outcomes compared with deceased donor transplantation in terms of the allograft and patient survival. Lack of published evidence until the last decade regarding the survival benefit of preemptive renal transplantation may have resulted in later referrals of patients to transplant centers until the initiation of renal replacement therapy. The authors have summarized the published studies about preemptive transplantation in Table 1 and will discuss each study briefly. These studies did not focus mainly on diabetic patients and used USRDS or UNOS databases.

Earlier retrospective and single-center studies involving small numbers of patients transplanted between 1970s and 1980s showed conflicting results regarding the beneficial effects of preemptive transplantation on allograft outcome [17-19]. The impact of pretransplant dialysis on patient and graft survival first was studied in a large single-center study by Cosio and colleagues [20] involving 523 kidney transplant recipients. Only 7\% of preemptively transplanted recipients died during follow-up compared with $23 \%$ of patients dialyzed for less than 3 years and $44 \%$ dialyzed for more than 3 years. The authors also reported that increasing time on dialysis increases the prevalence of left ventricular hypertrophy and cardiomegaly. The type of dialysis did not impact patient outcome. Another single-center study, analyzing 385 preemptive and 1464 nonpreemptive adult primary kidney transplant recipients, demonstrated a significant difference in the 5-year patient survival: $92.6 \%$ versus $76.6 \%$ in deceased donor and $93.3 \%$ versus $89.5 \%$ in living donor transplants, respectively [21]. Graft survival was increased in preemptive living donor recipients but not in deceased donor recipients.

Meier-Kriesche and colleagues [22] analyzed 73,103 primary adult renal transplant registered in the United States Renal Data System (USRDS) registry between 1988 and 1997 to investigate the effect of waiting time on renal transplant outcome. The authors showed that relative to preemptive transplants, waiting times on dialysis of 6 to 12,12 to 24,24 to 36,36 to 48 , and 
Table 1

Preemptive kidney transplantation

\begin{tabular}{|c|c|c|c|}
\hline Author & Database & $\begin{array}{l}\text { Patient } \\
\text { number }\end{array}$ & Outcome \\
\hline Cosio [20] & $\begin{array}{l}\text { Ohio State } \\
\text { University } \\
1984-1991\end{array}$ & 523 & $\begin{array}{l}\uparrow \text { mortality and } \uparrow \mathrm{LVH} \text { with } \\
\text { duration of pretransplant dialysis }\end{array}$ \\
\hline Mange $[24,25]$ & $\begin{array}{l}\text { USRDS } \\
\quad 1994-1997\end{array}$ & 9130 & $\begin{array}{l}\uparrow \mathrm{GS} \text { and } \downarrow \mathrm{AR} \text { with } \\
\text { preemptive } \mathrm{KTx}\end{array}$ \\
\hline Papalois [21] & $\begin{array}{r}\text { University of } \\
\text { Minnesota } \\
\text { 1984-1998 }\end{array}$ & 1849 & $\begin{array}{l}\uparrow \mathrm{PS} \text { in preemptive } \mathrm{KTx} \text { and } \uparrow \mathrm{GS} \\
\text { in preemptive living donor } \mathrm{KTx}\end{array}$ \\
\hline Vats [30] & $\begin{array}{l}\text { NAPRTCS } \\
1992-1996\end{array}$ & 2495 & $\begin{array}{l}\uparrow \mathrm{GS} \text { in preemptive pediatric } \\
\text { living donor KTx }\end{array}$ \\
\hline $\begin{array}{l}\text { Meier-Kreische } \\
\text { [22] }\end{array}$ & $\begin{array}{l}\text { USRDS } \\
\quad 1988-1997\end{array}$ & 73,103 & $\begin{array}{l}\uparrow \text { mortality and } \downarrow \text { GS with } \\
\text { increased duration on dialysis }\end{array}$ \\
\hline $\begin{array}{l}\text { Meier-Kreische } \\
\text { [23] }\end{array}$ & $\begin{array}{l}\text { USRDS } \\
\quad 1988-1998\end{array}$ & $\begin{array}{l}2405 \\
\quad \text { (paired donors) }\end{array}$ & $\begin{array}{l}\uparrow \text { mortality and } \downarrow \text { GS with } \\
\text { increased duration on dialysis }\end{array}$ \\
\hline Kasiske [16] & $\begin{array}{l}\text { UNOS and } \\
\text { USRDS } \\
1995-1998\end{array}$ & 38,836 & $\begin{array}{l}\downarrow \text { mortality and } \uparrow \text { GS with } \\
\text { preemptive KTx }\end{array}$ \\
\hline Ishani [27] & $\begin{array}{l}\text { USRDS } \\
\quad 1994-2000\end{array}$ & 4,046 & $\begin{array}{l}\text { No benefit of residual renal } \\
\text { function on post-transplant GFR }\end{array}$ \\
\hline Gill [28] & $\begin{array}{l}\text { USRDS } \\
\quad 1987-1996\end{array}$ & 40,063 & $\begin{array}{l}\text { No benefit of residual renal } \\
\text { function on post-transplant GFR }\end{array}$ \\
\hline Innocenti [29] & $\begin{array}{c}\text { Mayo Clinics } \\
2000-2002\end{array}$ & 438 & $\begin{array}{l}\text { Similar mortality and GS in } \\
\text { preemptive and nonpreemptive KTx }\end{array}$ \\
\hline
\end{tabular}

Abbreviations: AR, acute rejection; GFR, glomerular filtration rate; GS, graft survival; HD, hemodialysis; KTx, kidney transplantation; LVH, left ventricular hypertrophy; NAPRTCS, North American Pediatric Renal Transplantation Cooperative Study; PS, patient survival; UNOS, United Network for Organ Sharing; USRDS, United States Renal Data System.

over 48 months conferred a $21 \%, 28 \%, 41 \%, 53 \%$, and $72 \%$ increase in mortality risk after transplantation, respectively. This study found a timedependent detrimental effect of dialysis on patient survival, but also the graft survival, where patients on dialysis more than 2 years had a $68 \%$ increased risk of death-censored graft loss. The authors subsequently published a paired kidney donor analysis model, where one kidney of the pair went to a patient who had been on dialysis for less than 6 months, and the other kidney went to a patient who had been on dialysis for longer than 2 years, to avoid potential donor-related confounding factors [23]. This study excluded patients who had an HLA-identical or zero-antigen mismatched kidney transplant. The data analysis of 2405 kidney pairs harvested from the same donor between 1988 and 1998 revealed that recipients who had less than 6 months of dialysis before transplant had much better 5and 10-year unadjusted allograft survival rates than those who had greater than 2 years on dialysis ( $78 \%$ and $63 \%$ versus $58 \%$ and $29 \%$, respectively). Ten-year graft survival in deceased donor recipients was shown to be $69 \%$ for preemptive transplants and 39\% for patients after 24 months of 
hemodialysis. In living transplants, preemptive transplantation resulted in $75 \% 10$-year allograft survival, which decreased to $49 \%$ for those on pretransplant hemodialysis for more than 24 months. The authors concluded that waiting time on dialysis is the strongest independent modifiable risk factor for renal transplant outcomes. This effect is so significant that even deceased donor recipients who were on dialysis for less than 6 months had graft survival equivalent to living donor recipients who were on dialysis for more than 2 years.

Kasiske and colleagues [16] reviewed the data of 38,836 first kidney-only transplants between 1995 and 1998. In adjusted Cox proportional hazard analysis, the relative risk of graft failure for preemptive transplantation was 0.75 ( 0.67 to 0.84 ) among 25,758 deceased donor transplants and 0.73 (0.64 to 0.83 ) among 13,708 living donor transplants, compared with patients who received a transplant after initiating dialysis. Preemptive transplantation also was associated with a reduced risk of death: 0.84 (0.72 to $0.99)$ for deceased donor transplants and $0.69(0.56$ to 0.85$)$ for living donor transplants.

How does preemptive transplantation improve patient and graft survival after transplantation? The most plausible explanation is the avoidance of dialysis-associated morbidities with preemptive transplantation. The other explanation could be selection bias, where healthier, younger, more educated, and more compliant patients are more likely to receive preemptive transplantation. Other factors that have been investigated included acute rejection episodes and residual renal function. Mange and colleagues [24] analyzed the outcomes of 8481 first living donor kidney transplant recipients between January 1994 and June 1997 and reported that preemptive transplantation was associated with $52 \%, 82 \%$, and $86 \%$ reductions in the risk of allograft failure during the first, second, and subsequent years after transplantation, respectively. Interestingly, increasing duration of dialysis was associated with increasing odds of rejection within 6 months of transplantation. Renal biopsy-confirmed acute rejection rates during the first month were 2.5-fold higher among recipients of nonpreemptive living renal transplants compared with preemptive patients, even when accounting for high panel reactive antibody titers and delayed graft function [25]. These results suggest a stimulatory effect of the immune system by dialysis exposure before transplantation. $T$ cell activity has been shown to be suppressed in patients who have chronic kidney disease, and the initiation of dialysis may improve the $\mathrm{T}$ cell proliferation and responsiveness to alloantigen. Increased levels of $\mathrm{T}$ cell activation markers and complement cascade caused by exposure to dialysis membranes also have been suggested [26].

Residual renal function improves outcome in hemodialysis and peritoneal dialysis patients and is thought to play role in better outcomes with preemptive transplantation. Two studies, however, failed to confirm that higher levels of pretransplant GFR are associated with improved outcomes. Ishani and colleagues [27] retrospectively reviewed the USRDS data of living 
donor transplant recipients between 1994 and 2000. There were no differences in allograft survival and 6-month post-transplant estimated GFR, when patients with pretransplant GFR greater than or equal to $15 \mathrm{~mL} / \mathrm{min}$ were compared with patients with GFR levels less than $15 \mathrm{~mL} / \mathrm{min}$. Gill and colleagues [28] compared 6-month GFR levels after transplantation in 5966 preemptive transplant recipients with 34,997 nonpreemptive transplant recipients, and found no difference ( 49.5 versus $49.2 \mathrm{~mL} / \mathrm{min}$, respectively). Both groups had a similar rate of decline in kidney function after transplantation.

The Minnesota Mayo Clinic group reported a high preemptive living donor transplant rate $(44 \%)$ in patients transplanted between 2000 and 2002 [29]. This study excluded highly sensitized patients with positive cross-matches and ABO-incompatible transplants. There was no difference in patient survival at 3 years in diabetic preemptive and nonpreemptive patients ( $88 \%$ versus $89 \%$, respectively). Preemptive transplant recipients had higher 3-year graft survival compared with nonpreemptive recipients ( $97 \%$ versus $90 \%$, respectively) but the difference was not statistically significant by multivariate analysis, probably because of the small number of patients. The beneficial effect of preemptive kidney transplantation in graft survival was shown in pediatric primary living kidney transplant recipients between 1992 and 1996 [30].

\section{Preemptive kidney/pancreas transplantation}

Diabetic kidney transplant recipients have lower patient survival compared with kidney transplant recipients without diabetes. The SPK has been advocated to improve survival in diabetic patients. A study by Ojo and colleagues [31] evaluating 13,467 diabetic patients showed $67 \% 10$ year patient survival in SPK recipients, compared with $46 \%$ in recipients of deceased donor kidneys alone. Reddy and colleagues [32] reviewed the UNOS database of 18,459 type 1 diabetic patients transplanted between 1987 and 1996, and reported increased 8-year patient survival in SPK recipients $(72 \%)$ compared with patients receiving only deceased donor kidney transplantation $(55 \%)$. SPK has been hypothesized to improve kidney allograft survival by better glycemic control and shorter cold ischemia time, leading to decreased delayed graft function. There are only three studies that investigated the effects of preemptive SPK on allograft outcome (Table 2) [33-35].

Israni and colleagues [33] examined UNOS data for 8323 diabetic patients waitlisted for SPK and received either SPK or kidney transplantation alone to avoid the selection bias of healthier patients listed for SPK compared with diabetic patients listed for only kidney transplantation. SPK recipients had adjusted risk ratio (RR) for kidney allograft loss of 0.63 (0.51 to $0.77, P<.001)$ compared with kidney transplant recipients without pancreas 
Table 2

Preemptive simultaneous pancreas and kidney transplantation

\begin{tabular}{lcrl}
\hline Israni [33] & SRTR 1990-2002 & 8323 & $\uparrow$ GS in preemptive SPK \\
Becker [34] & SRTR 1997-2002 & 23,328 & $\begin{array}{l}\uparrow \text { GS in SPK, } \downarrow \text { mortality risk in } \\
\text { DM I and DM II with preemptive KTx }\end{array}$ \\
Pruijm [35] & $\begin{array}{c}\text { Leiden University } \\
1986-2004\end{array}$ & 180 & $\begin{array}{l}\uparrow \text { PS in preemptive SPK, no change in GS } \\
\end{array}$
\end{tabular}

Abbreviations: GS, graft survival; KTx, kidney transplantation; PS, patient survival; SPK, simultaneous pancreas kidney transplantation; SRTR, Scientific Registry for Transplant Recipients.

allograft. Preemptive SPK recipients demonstrated a lower rate of allograft loss compared with SPK recipients transplanted after initiation of dialysis [RR $=0.83$ (0.69 to $0.99, P=.042$ )], even though the duration of pretransplant dialysis was less than 2 years in $70 \%$ of the nonpreemptive recipients.

Becker and colleagues [34] investigated the impact of preemptive kidney transplantation on patient and graft survival in 23,238 adult type 1 and 2 diabetic patients receiving a first kidney transplantation alone or SPK, analyzing data from the Scientific Registry of Transplant Recipients between 1997 and 2002. Preemptive kidney transplantation was provided to $14.4 \%$ type 1 and $6.7 \%$ type 2 diabetic patients. Preemptive SPK and preemptive living kidney alone transplantation conferred significantly lower adjusted mortality risks for type 1 diabetic patients ( $R R, 0.50$ and 0.57 , respectively). The mortality benefit of preemptive kidney transplantation was also evident for type 2 diabetic patients (RR, 0.65). Preemptive SPK was associated with lower risk for allograft loss $(R R=0.79)$. Preemptive kidney transplantation, however, did not affect graft survival in type 2 diabetic patients, although there was a trend toward lower risk for type 2 living donor recipients (RR, $0.081 ; P=.09$ ). This somewhat differed from the analysis by MeierKriesche examining an earlier cohort of patients (1988 to 1997). The reasons for this discrepancy could be attributed to different immunosuppressive regimens, decreasing acute rejection rates over time, and different comorbid conditions of the patients receiving transplantation.

A recent single-center study from the Netherlands comparing preemptive versus nonpreemptive SPK showed a survival benefit and decreased cardiovascular deaths in preemptive patients [35]. This study involved 180 patients who received SPK between 1986 and 2004. Sixty-five patients (36\%) were transplanted preemptively. Ten- and 15 -year patient survivals were $71.3 \%$ and $64.8 \%$ in the preemptive group, compared with $63.8 \%$ and $45 \%$ in the nonpreemptive group, leading to an RR for mortality of $0.50(P=$ $.07)$. The difference was not statistically significant, probably because of the number of patients studied. There was no difference in kidney and pancreas allograft survival between the two groups. The mean GFR at the time of transplantation was $21.4 \mathrm{~mL} / \mathrm{min}$, which is higher than expected, where patients start on dialysis when the GFR is less than $15 \mathrm{~mL} / \mathrm{min}$ in diabetics. 
Patients on the waiting list for kidney transplantation start to recruit time when the GFT is less than $20 \mathrm{~mL} / \mathrm{min}$ in the United States.

\section{Summary}

Kidney transplantation is the best treatment for ESRD. It improves not only patient life expectancy, but also the quality of life. Preemptive transplantation further improves patient and graft survival by avoiding dialysis-related morbidities, including the increased risks of cardiovascular disease and infection. Transplantation also brings economic advantages to health care system. The most important factor is the early referral of patients with chronic kidney disease to nephrologists and transplant centers to discuss the options for renal replacement therapy. Patients should start work up for transplantation when the GFR reaches $30 \mathrm{~mL} / \mathrm{min}$ or if there is inevitable and predictable decline in renal function, so that they may receive kidney transplantation before initiation of dialysis.

\section{Acknowledgment}

The authors thank Dr. Jonathan S. Bromberg for critical review of the manuscript.

\section{References}

[1] King H, Aubert R, Herman WH. Global burden of diabetes, 1995-2025. Diabetes Care 1998;21:1414-31.

[2] Annual report. USRDS 2006.

[3] United Network for Organ Sharing Web site. Available at: www.unos.org.

[4] Mange KC, Weir M. Preemptive renal transplantation: why not? Am J Transplant 2003;3: $1336-40$.

[5] Meier-Kriesche H, Schold JD. The impact of pretransplant dialysis on outcomes in renal transplantation. Semin Dial 2005;18(6):499-504.

[6] Muntner P, He J, Hamm L, et al. Renal insufficiency and subsequent death resulting from cardiovascular disease in the United States. J Am Soc Nephrol 2002;13:745-53.

[7] Sarnak MJ, Levey AS. Cardiovascular disease and chronic renal disease: a new paradigm. Am J Kidney Dis 2000;35(4 Suppl 1):S117-31.

[8] Wolfe R, Ashby VB, Milford EL. Comparison of mortality in all patients on dialysis, patients on dialysis awaiting transplantation, and recipients of a first cadaveric transplant. N Engl J Med 1999;341(23):1725-30.

[9] Ojo AO, Hanson JA, Meier-Kreische HU, et al. Survival in recipients of marginal cadaveric donor kidneys compared with other recipients and wait-listed transplant candidates. J Am Soc Nephrol 2001;12:589-97.

[10] Glanton CW, Kao TC, Cruess D, et al. Impact of renal transplantation on survival in endstage renal disease patients with elevated body mass index. Kidney Int 2003;63:647-53.

[11] McDonald SP, Russ GR. Survival of recipients of cadaveric kidney transplants compared with those receiving dialysis treatment in Australia and New Zealand, 1991-2001. Nephrol Dial Transplant 2002;17:2212-9.

[12] Schnuelle P, Lorenz D, Trede M, et al. Impact of renal cadaveric transplantation on survival in end-stage renal failure: evidence for reduced mortality risk compared with hemodialysis during long-term follow-up. J Am Soc Nephrol 1998;9:2135-41. 
[13] Meier-Kriesche H, Schold J, Srinivas TR, et al. Kidney transplantation halts cardiovascular disease progression in patients with end-stage renal disease. Am J Transplant 2004;4:1662-8.

[14] Weng FL, Mange KC. A comparison of persons who present for preemptive and nonpreemptive kidney transplantation. Am J Kidney Dis 2003;42(5):1050-7.

[15] Arora P, Obrador G, Ruthazer R. Prevalence, predictors, and consequences of late nephrology referral at a tertiary care center. J Am Soc Nephrol 1999;10:1281-6.

[16] Kasiske BL, Snyder JJ, Matas AJ, et al. Preemptive kidney transplantation: the advantage and the advantaged. J Am Soc Nephrol 2002;13:1358-64.

[17] Migliori RJ, Simmons RL, Payne WD, et al. Renal transplantation done safely without prior chronic dialysis therapy. Transplantation 1987;43(1):51-5.

[18] Katz SM, Kerman RH, Golden D, et al. Preemptive transplantation-an analysis of benefits and hazards in 85 cases. Transplantation 1991;51(2):351-5.

[19] Roake JA, Cahill AP, Gray CM, et al. Preemptive cadaveric renal transplantation-clinical outcome. Transplantation 1996;62(10):1411-6.

[20] Cosio FG, Alamir A, Yim S, et al. Patient survival after renal transplantation: the impact of dialysis pretransplant. Kidney Int 1998;53:767-72.

[21] Papalois VE, Moss A, Gillingham KJ, et al. Preemptive transplants for patients with renal failure. Transplantation 2000;70(4):625-31.

[22] Meier-Kriesche H, Port FK, Ojo AO, et al. Effect of waiting time on renal transplantation outcome. Kidney Int 2000;58:1311-7.

[23] Meier-Kriesche H, Kaplan B. Waiting time on dialysis as the strongest modifiable risk factor for renal transplantation outcomes: a paired donor kidney analysis. Transplantation 2002; 74(10): 1377-81.

[24] Mange K, Joffe M, Feldman HL. Effect of the use or nonuse of long-term dialysis on the subsequent survival of renal transplants from living donors. N Engl J Med 2001;344(10):726-31.

[25] Mange KC, Joffe MM, Feldman HI. Dialysis prior to living donor kidney transplantation and rates of acute rejection. Nephrol Dial Transplant 2003;18:172-7.

[26] Kaul GM, Sester U, Sester M, et al. Initiation of hemodialysis treatment leads to improvement of T cell activation in patients with end-stage renal disease. Am J Kidney Dis 2000;35: 611-6.

[27] Ishani A, Ibrahim H, Gilbertson D, et al. The impact of residual renal function on graft survival and patient survival rates in recipients of preemptive renal transplants. Am J Kidney Dis 2003;42(6): 1275-82.

[28] Gill JS, Tonelli M, Johnson N, et al. Why do preemptive kidney transplant recipients have an allograft survival advantage? Transplantation 2004;78(6):873-9.

[29] Innocenti GR, Wadei HM, Prieto M, et al. Preemptive living donor kidney transplantation. Transplantation 2007;83(2):144-9.

[30] Vats A, Donaldson L, Fine R, et al. Pretransplant dialysis status and outcome of renal transplantation in North American children: an NAPRTCS study. Transplantation 2000;69: $1414-9$.

[31] Ojo AO, Meier-Kriesche H, Hanson J, et al. The impact of simultaneous pancreas-kidney transplantation on long-term patient survival. Transplantation 2001;71:82-90.

[32] Reddy SK, Stablein D, Taranto S, et al. Long-term survival following simultaneous kidneypancreas transplantation alone versus kidney transplantation alone in patients with type 1 diabetes mellitus and renal failure. Am J Kidney Dis 2003;41(2):464-70.

[33] Israni AK, Feldman HI, Propert KJ, et al. Impact of simultaneous kidney-pancreas transplant and timing of transplant on kidney allograft survival. Am J Transplant 2005;5:374-82.

[34] Becker B, Rush SH, Dykstra D, et al. Preemptive transplantation for patients with diabetesrelated kidney disease. Arch Intern Med 2006;166:44-8.

[35] Pruijm MT, de Fijter HJW, Doxiadis II, et al. Preemptive versus nonpreemptive simultaneous pancreas-kidney transplantation: a single-center, long-term, follow-up study. Transplantation 2006;81(8):1119-24. 